\title{
A Monochromatic Low-Latitude Aurora
}

\author{
F. E. Roach and E. Marovich
}

(May 28, 1959)

\begin{abstract}
A monochromatic (6300 A) auroral are occurred over Colorado on September 29/30, 1957. It seems to have been a continuation of a similar arc observed at Haute Provence, France, on the same night. Its intensity decreased during the night from about 7,000 rayleighs to 2,000 rayleighs compared with a normal zenith intensity of 100 to 200 rayleighs. It was relatively fixed (geographically) during the night, south of and apparently independent of a visual aurora that was active to the north from 0100 to 0400 m.s.t. The magnetic dipole lines of force from the arc extend out into space between the two Van Allen radiation belts. It is speculated that the arc may be associated with one of the belts.
\end{abstract}

\section{Introduction}

In a recent study of low-latitude auroral activity, Barbier $[1]^{1}$ has reported on observations at the Haute Provence Observatory (longitude 5 ${ }^{\circ} 43^{\prime} \mathrm{E}$; latitude $+43^{\circ} 56^{\prime}$; geomagnetic latitude $45.9^{\circ}$ ). He found evidence for a "monochromatic" (6300 A) aurora during 31 nights over the period from March 10, 1956 to September 29, 1957. In general, these auroras were not conspicuous visually because of the relative insensitivity of the eye to the red.

Barbier operates three different photometers at Haute Provence. One utilizes eight different filters and is fixed in orientation toward the celestial pole (with reference observations at the zenith). The other two cover the sky in almucantars, usually at a zenith distance of $75^{\circ}$. The almucantar sweeps show two distinct types of 6300 auroral activity: (1) a pronounced increase in brightness in the general northerly direction; and (2) an increase in brightness at two different azimuths one a little north of west and the other a little north of east. The second type may be accompanied by an increase in the brightness at the celestial pole but not appreciably at the zenith. Barbier's interpretation of these double maximums is that there is a 6300 arc extending roughly from east to west across the sky, crossing the meridian somewhere between the zenith and the northern horizon.

On one of the four nights during which such an arc was observed at the Haute Provence Observatory (September 29/30, 1957), we obtained independent evidence at Fritz Peak (longitude $105^{\circ} 29^{\prime} 25^{\prime \prime} \mathrm{W}$; latitude $39^{\circ} 54^{\prime} 34^{\prime \prime} \mathrm{N}$; geomagnetic latitude $49^{\circ}$ ) that a similar 6300 arc occurred. We were observing 6300 along the geographic meridian from borizon to horizon and were not operating a 6300 photometer in almucantars. We did have 5577 photometers observing the sky in a series of almucantars both at Fritz Peak and at the Rapid City IGY station (longitude $103^{\circ} 18^{\prime} 50^{\prime \prime} \mathrm{W}$; latitude $44^{\circ} 01^{\prime} \mathrm{N}$; geomagnetic latitude $53^{\circ}$ ).

1 Figures in brackets indicate the literature references at the end of this paper.
During the night a visual aurora was observed to the north of both American stations with a peak intensity at approximately 0215 m.s.t. A striking feature of the night was the isolation of a very pronounced maximum of intensity of 6300 near the zenith at Fritz Peak, as illustrated in figure 1. At the start of the night, the observer (L. R. Megill) noted that the 6300 records were off scale near the zenith and after moonset (2200 m.s.t.) he was convinced that an unusual event was occurring. The sensitivity of the photometer was reduced to keep the peak zenith deflection on scale. Visual inspec-

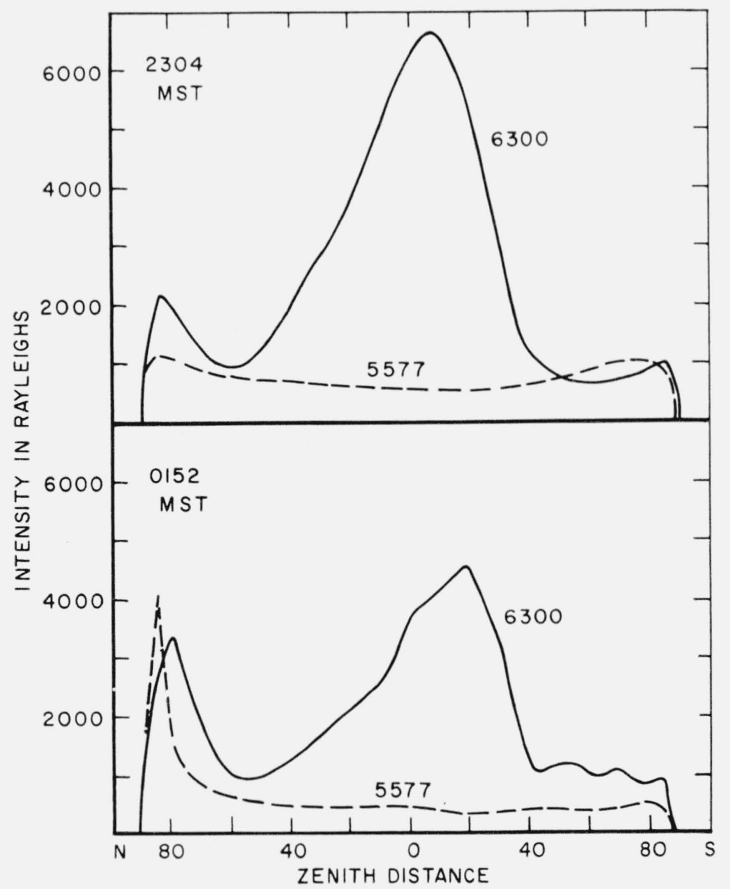

Figure 1. Meridian sweeps at Fritz Peak of 6300 and $557 \%$ at 2304 m.s.t. and 0152 m.s.t. 
tion of the sky did not show any apparent zenith brightening, which subsequently was explained as due to the fact that, in agreement with Barbier's interpretation, this was a monochromatic emission (5577 for example showed no zenith enhancement at all) and, though physically bright (about 7,000 rayleighs), was nevertheless below the visual threshold for red light. ${ }^{2}$ The usual zenith intensity of 6300 is 100 to 200 rayleighs so that the observed arc is some 50 times normal.

From our observations alone, it is not possible to infer an arc structure from the zenith enhancement of 6300 in horizon to horizon sweeps in the meridian. But it is reasonable to assume such a structure when our records are interpreted in the light of Barbier's results.

\section{Variation of the Peak Intensity with Time}

The 6300 arc at Fritz Peak slowly decreased in intensity during the night. In figure 2, we show the variation of the peak intensity of 6300 above the background and, for comparison, the results of Barbier at Haute Provence. We note that the end of the observing night at Haute Provence coincides almost exactly with the start at Fritz Peak.

The physical picture suggested by these observations is that a 6300 arc persisted in time over at least $12 \mathrm{hr}$ and in space at least $110^{\circ}$ in longitude or approximately one-third of the way around the world (fig. 3).

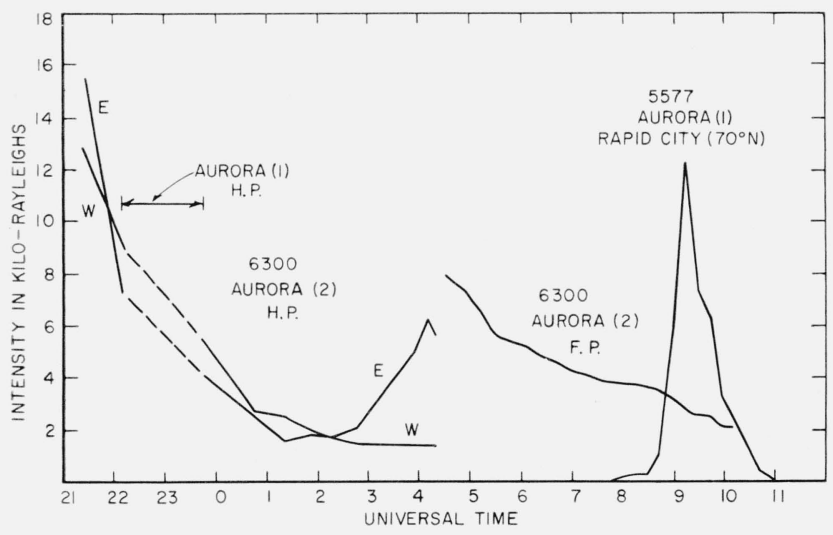

Figure 2. Variation of intensity of the 6300 aurora at Haute Provence and Fritz Peak on September 29/30, $195 \%$.

A localized northern aurora at Haute Provence is indicated between $22^{\mathrm{h}}$ and $24^{\mathrm{h}}$ u.t. (Sept. 29) and at Rapid City, north of Fritz Peak, between $8^{\mathrm{h}}$ and $11^{\mathrm{h}} \mathrm{u}$.t. (Sept. 30).

\section{Position of the Maximum}

We have measured the zenith distance of the maximum intensity on our records with the results shown in table 1 (col. 2) and in figure 4. There is a

\footnotetext{
${ }^{2}$ It has been our experience that 1,000 rayleighs is the effective visual threshold for the green part of the spectrum. At $6300 \mathrm{~A}$ the threshold should be much higher than in the green since the dark-adapted eye is almost inert to the longer
} wavelengths.

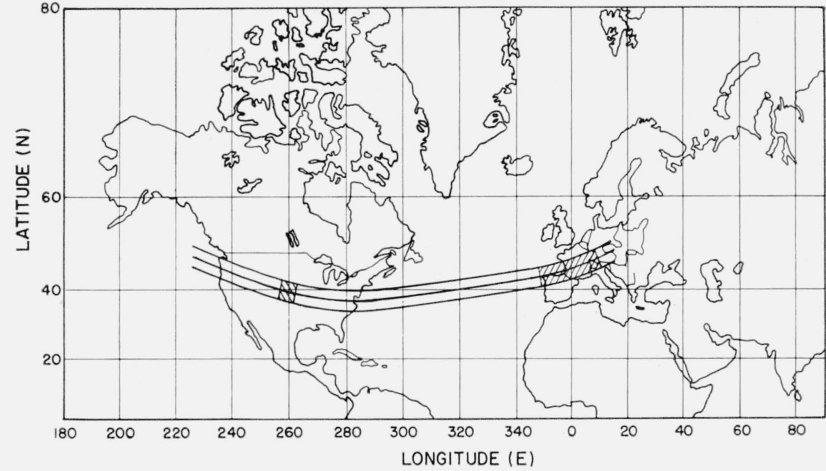

Figure 3. Suggested extent of 6300 arc on September 29/30, $195 \%$.

Shaded portions are actually observed at Haute Provence and Fritz Peak.

TABLe 1

\begin{tabular}{|c|c|c|c|c|c|}
\hline $\begin{array}{l}\text { Mountain } \\
\text { standard } \\
\text { time }\end{array}$ & $\begin{array}{c}\text { Position of } \\
\text { maximum-- } \\
\text { degrees south } \\
\text { of zenith }\end{array}$ & $\begin{array}{l}\text { Intensity } \\
\text { of maxi- } \\
\text { mum }\end{array}$ & $\begin{array}{l}\text { Mountain } \\
\text { standard } \\
\text { time }\end{array}$ & $\begin{array}{c}\text { Position of } \\
\text { maximum-- } \\
\text { degrees south } \\
\text { of zenith }\end{array}$ & $\begin{array}{l}\text { Intensity } \\
\text { of maxi- } \\
\text { mum }\end{array}$ \\
\hline 2134 & & $(7870)$ & 0030 & 5.0 & 4000 \\
\hline 2142 & & $(7630)$ & 0038 & 4. 0 & 3790 \\
\hline 2150 & & $(7460)$ & 0046 & 4.5 & 3770 \\
\hline 2158 & & $(7410)$ & & & \\
\hline 2206 & & $(6850)$ & 0054 & 4.5 & 3800 \\
\hline 2214 & & $(6390)$ & $\begin{array}{l}0102 \\
0110\end{array}$ & $\begin{array}{l}5.5 \\
6.0\end{array}$ & $\begin{array}{l}3710 \\
3760\end{array}$ \\
\hline 2222 & & $(6230)$ & 0118 & 7.0 & 3680 \\
\hline 2230 & 3.5 & 5430 & 0126 & 8.0 & 3710 \\
\hline 2238 & 3.0 & 5390 & & & \\
\hline 2246 & 4.0 & 5390 & 0134 & 10.0 & 3710 \\
\hline 2254 & 5,5 & 5420 & $\begin{array}{l}0142 \\
0150\end{array}$ & $\begin{array}{r}8.0 \\
14.0\end{array}$ & $\begin{array}{l}3550 \\
3490\end{array}$ \\
\hline 2302 & $\begin{array}{l}0.0 \\
6.0\end{array}$ & 5290 & 0158 & $\begin{array}{l}14.0 \\
13.0\end{array}$ & $\begin{array}{l}3490 \\
3160\end{array}$ \\
\hline 2310 & 7.0 & 5120 & 0206 & 11.5 & 2980 \\
\hline 2318 & 6.5 & 5000 & & & \\
\hline 2326 & 5.5 & 4810 & 0214 & 9.5 & 2800 \\
\hline & & & 0222 & 16.0 & 2420 \\
\hline 2334 & 7.5 & 4690 & 0230 & 14.5 & 2510 \\
\hline 2342 & 5.5 & 4520 & 0238 & 14.0 & 2650 \\
\hline 2350 & 5.5 & 4360 & 0246 & 10.5 & 2390 \\
\hline 2358 & 5.0 & 4300 & & & \\
\hline 0006 & 1.0 & 4260 & 0254 & 15.0 & 2140 \\
\hline & & & $\begin{array}{l}0302 \\
0310\end{array}$ & 13.0 & $\begin{array}{l}2030 \\
2020\end{array}$ \\
\hline 0022 & $\begin{array}{l}3.0 \\
4.0\end{array}$ & $\begin{array}{l}4140 \\
4040\end{array}$ & 0310 & 16.0 & 2020 \\
\hline
\end{tabular}

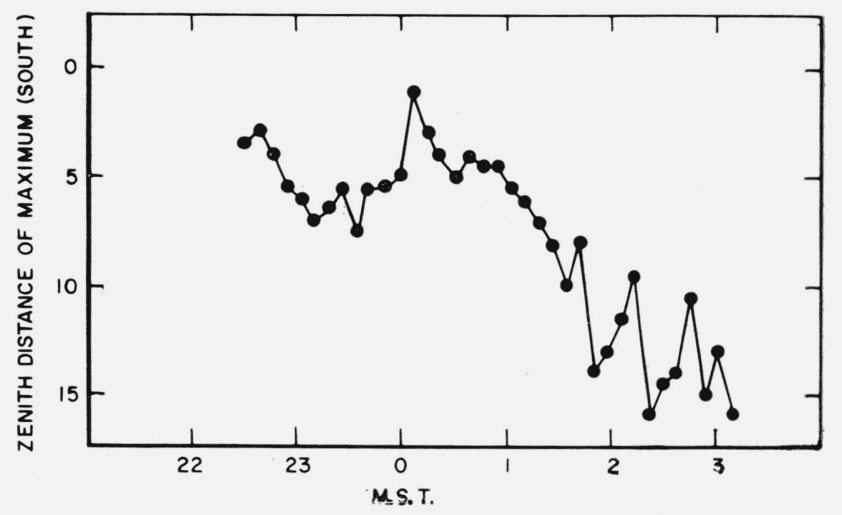

Figure 4. Variation of position of the 6300 peak observed at Fritz Peak during the night of September 29/30, $195 \%$. 
systematic southerly movement from midnight to $03^{\mathrm{h}}$. If this is interpreted as a geographical movement ana if we assume an emission height of $300 \mathrm{~km}$, the total geographical excursion of the photometric center of the arc is only about $80 \mathrm{~km}$, or less than $1^{\circ}$ of latitude (corresponding to a change of zenith distance from $1^{\circ} \mathrm{S}$ to $16^{\circ} \mathrm{S}$ ). Between midnight and $03^{\mathrm{h}}$, the mean speed of movement was about 6.5 $\mathrm{m} / \mathrm{sec}$ and again assuming a $300-\mathrm{km}$ height.

The center of the arc in Colorado was within $1^{\circ}$ of the geomagnetic latitude of Fritz Peak $\left(49^{\circ}\right)$ during the entire night. If the center of the are at Haute Provence was at a northerly zenith distance of about $50^{\circ}$, it would be about $3^{\circ}$ north of Haute Provence $\left(\Phi=46^{\circ}\right)$ or also at a geomagnetic latitude of $49^{\circ}$.

The southern migration of the peak may be the result of the fact that the northern side of the photometric curve steadily moves southward. The southern side seems to remain constant. The result is an apparent movement of the peak (fig. 5).

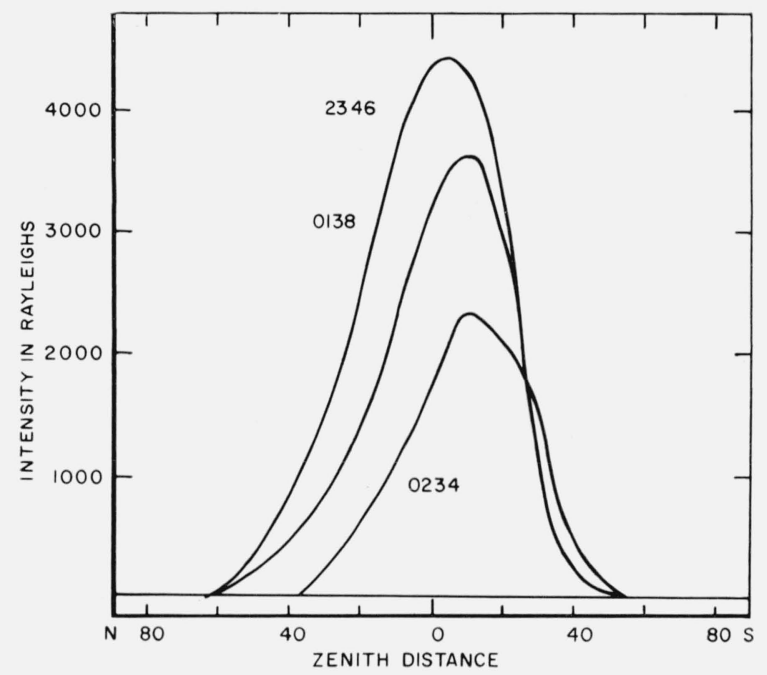

Figure 5. Evolution of the 6300 arc at Fritz Peak during the night of September 29/30, $195^{7}$.

\section{Width of the Arc}

The southern and northern extremes of the arc are fairly well defined on the records; hence, the extreme width of the arc can be estimated. If the height is fixed at $300 \mathrm{~km}$, the mean width is $800 \mathrm{~km}$. The half-intensity width is about $250 \mathrm{~km}$. Barbier estimated the arc in France to have an extension of about $500 \mathrm{~km}$. In section 7 we suggest however that there is a significant extension in height in which case these width estimates are too high.

\section{Is the 6300 Arc Associated With the Northerly Aurora?}

There was a well-defined aurora (which we shall designate Aurora (2)) near the northern horizon at both Haute Provence and Fritz Peak during the night in question as indicated in figure 1 . So far as the intensity of the 6300 arc is concerned, there is no evidence at either station that it is influenced by the coincident northern aurora. The northern (5577) aurora peaks beyond the extreme $\left(z=80^{\circ}\right)$ observation at Rapid City which places it at least 470 $\mathrm{km}$ or $4.2^{\circ}$ to the north. This corresponds to $\Phi=57^{\circ}$. The two phenomena are thus separated by at least $8^{\circ}$ of latitude $(\approx 900 \mathrm{~km}$.)

Although the center of Aurora (2) in America is well to the north of even the northern extreme of the red arc, it is possibly significant that the southern edge of Aurora (2) is very close to the northern edge of the red arc (see fig. 6). The occurrence of the two phenomena on the same night and with their edges almost touching (geographically) suggests that there may be some connection between them. However, there is no definite evidence favoring any relationship and, as Barbier has indicated, "the evolution of the are is not at all influenced by the presence of another concomitant auroral phenomenon."

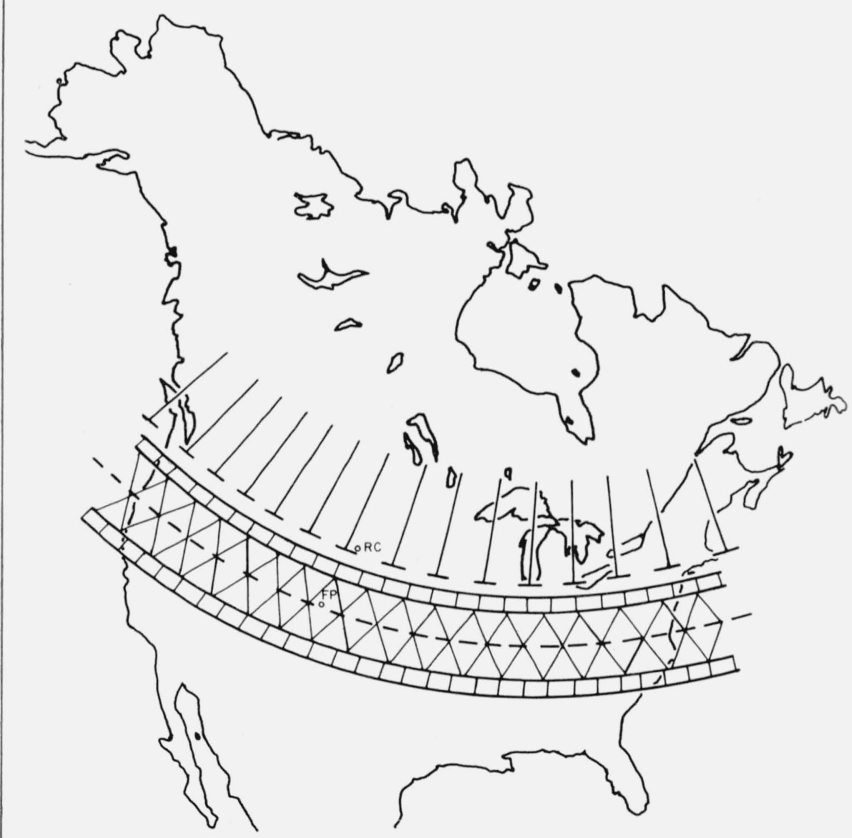

Figure 6. Relationship of the 6300 arc to the visual aurora. The shaded region is the 6300 arc and the $\perp \perp$ symbols indicate the southern extension of the visual aurora.

That the 6300 monochromatic auroras at Haute Provence are positively correlated with geomagnetic activity is shown by Barbier. However, he calls attention to the fact that at Tamanrasset (longitude $5^{\circ} 32^{\prime} \mathrm{E}$; latitude $+22^{\circ} 47^{\prime}$; geomagnetic latitude $+25.3^{\circ}$ ) there are many irregularities in the 6300 intensity. In the course of 2 or $3 \mathrm{hr}$, an increase by as much as a factor of 10 may occur. These are similar to, but much larger than, the variations which accompany the auroras at Haute Provence, but they occur more frequently and have no relationship to magnetic activity. 
According to Chapman [2] who has made a study of the occurrence of tropical auroras, their color is often conspicuously red. On one occasion (February 14,1848 ) an aurora was observed in India at a geomagnetic latitude of $+13^{\circ}$ at a time when there was no outstanding magnetic activity and no worldwide auroral display. We raise the question whether the tropical auroras (India, Tamanrasset) and the detached 6300 ares, as observed at Haute Provence and Fritz Peak on September 29/30, 1957, may be similar phenomena.

\section{A Possible Double-Aurora Mechanism}

The narrowness of the 6300 are suggests an analogy with localized features of the aurora. It is therefore of interest to consider it in relationship to the earth's magnetic field. In figure 7 we show an extension of the magnetic dipole lines of force for $\Phi=48.5^{\circ} \pm 3.0^{\circ}$ from the earth's surface out into space (region B). The two regions of concentrated radiation reported by Van Allen, McIlwain, and Ludwig [3] (A and C) are also shown, along with the magnetic line of force corresponding to the auroral zone $\left(\Phi=67^{\circ}\right)$. It is noted that the region B bears the same relationship to $\mathrm{A}$ as $\mathrm{D}$ to $\mathrm{C}$. This suggests the possibility that the inner region of ionization (A) may be responsible for our 6300 arc and the outer region (C) for the more northerly aurora. If region $\mathrm{C}$ received an energy surge simultaneously with A then the observations indicate that the release in the auroral zone was more sharply dependent on local time than that producing the 6300 are.

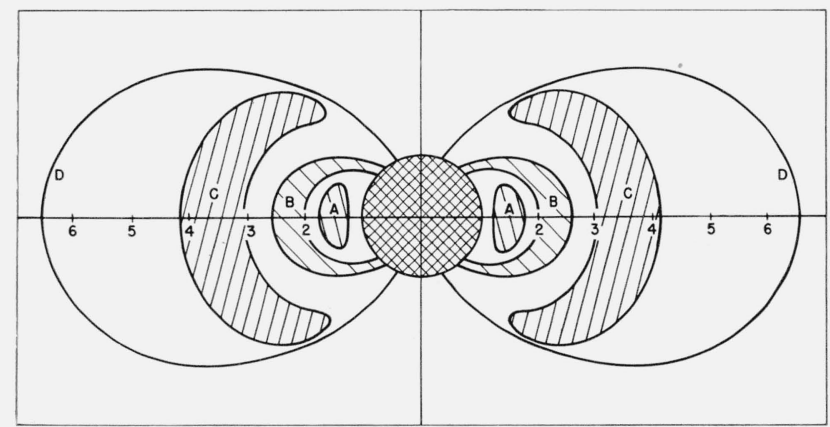

FIGURE 7. The extension of the magnetic dipole field lines $(B)$ corresponding to the terrestrial position of the 6300 arc.

(A) and (C) are the Van Allen regions of enhanced ionization. $D$ is the extension of the dipole line of force for the auroral zone $\left(\Phi=67^{\circ}\right)$.

The rate of decrease of intensity, $I$, noted by Barbier at Haute Provence is about twice that observed at Fritz Peak. Defining $\alpha$ by

$$
\alpha=\frac{-d \log _{e} I}{d t},
$$

he found $\alpha=1.1 \times 10^{-4} \mathrm{sec}^{-1}$. We find for Fritz Peak $\alpha \approx 0.6 \times 10^{-4} \mathrm{sec}^{-1}$. The rate of decrease of 6300 during the night under nonauroral conditions is comparable [4] with $\alpha=0.4 \times 10^{-4} \mathrm{sec}^{-1}$.

\section{Photometric Assymmetry of the Arc}

A characteristic of the arc as observed at Fritz Peak is that the southern edge is steeper than the northern. This is the sort of effect that could be expected if, in addition to an extension in latitude, there is a significant extension along the magnetic lines of force as shown in figure 8 . In both of the models shown in figure 8 , the maximum contribution to the brightness is assumed to occur at a height of $300 \mathrm{~km}$. In (a) the arc is shown with an extension in both altitude, (from 120 to $500 \mathrm{~km}$ ) along the geomagnetic lines of force, and latitude $(240 \mathrm{~km})$. In (b) a thin layer $(50 \mathrm{~km})$ is assumed with a horizontal extension of $560 \mathrm{~km}$.

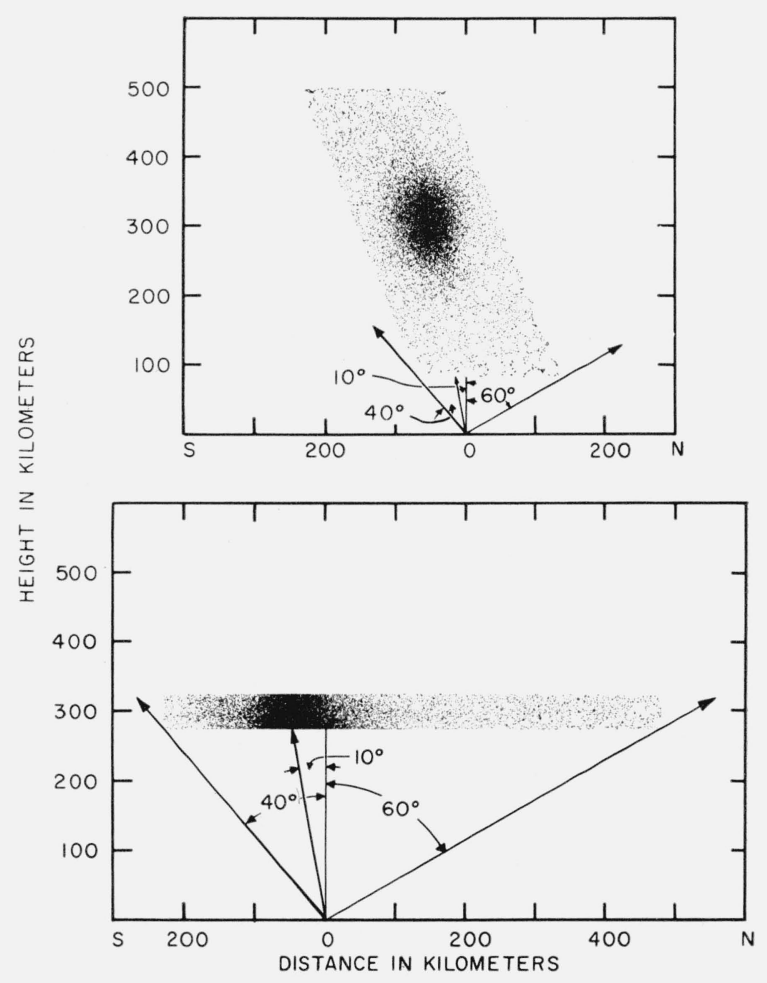

FIGURE 8. Two schematic models of the 6300 arc based on (a) peak intensity $10^{\circ} \mathrm{S},(\mathrm{b})$ southern extreme at $40^{\circ} \mathrm{S}$, and $(\mathrm{c})$ northern extreme at $60^{\circ} \mathrm{N}$.

\section{Conclusion}

We have made a preliminary examination of our records for similar monochromatic auroras on other occasions. On at least three other nights (September $21 / 22$, September $22 / 23$, and September 30/October 1, all in 1957), we have noted a considerable 6300 activity at Fritz Peak. There is evidence that the 6300 emission was significantly independent of 5577 on all these dates. September $21 / 22$ and $22 / 23$ were also active nights (6300) at Haute Provence. 
At Rapid City, we have also noted cases of a 6300 arc apparently detached from and to the south of the aurora proper. An outstanding example of this was October $22 / 23,1958$, a night which is currently under study by us.

It is not known whether 6300 ares occur as a general or as a sporadic fringe on the equatorial side of prominent visual auroras. Barbier [1] has made a statistical study of 6300 auroras at Haute Provence and finds that they occur during 9.8 percent of the observing time. Of 31 nights included in his list, four are listed as showing well-defined "arcs." Thus, distinct ares occurred during approximately $4 / 31 X$ $9.8=1.3$ percent of the observing time. According to Vestine [5], auroras at a latitude (geomagnetic) of $46^{\circ}$ are visible 1.5 percent of the time. Thus, it is not unreasonable to hypothesize that isolated 6300 ares are a general fringe feature of auroras. If indeed this is the case, a reexamination is in order of all auroral theories based on the assumption of a narrow, well-defined auroral zone.

\section{References}

[1] D. Barbier, L'activite aurorale aux basses latitudes, Ann. Geophys. 14, 334 (1958).

[2] S. Chapman, Polar and tropical aurorae and the isoauroral diagram, Proc. Indian Acad. Sci. 37, 175 (1953); The aurora in middle and low latitudes, Nature 179, 7 (1957); Auroral observations in India and Pakistan, Bull. Nat. Inst. Sci. (India) No. 9, 180 (1957).

[3] J. Van Allen, C. E. MeIlwain, and G. H. Ludwig, Radiation observations with satellite $1958 \epsilon$, J. Geoph. Research 64, 271 (1959) and Scientific American (March 1959).

[4] L. R. Megill, Ph. D. dissertation, A study of the atmospheric twilight emissions [OI] 5577 and [OI] 6300, University of Colorado (1959).

[5] E. H. Vestine, The geographic incidence of aurora and magnetic disturbance, northern hemisphere, Terrestrial Magnetism Atmospheric Elec. 49, 77 (1944).

Boulder, Colo.

(Paper 63D3-26) 